\title{
Revealing Hydrogen Bond Dynamics between Ion Pairs in Binary and Reciprocal Ionic Liquid Mixtures
}

\author{
Pratik Dhakal, Sudip Kumar Das and Jindal K.Shah* \\ School of Chemical Engineering, Oklahoma State University, Stillwater, Oklahoma,74078, \\ United States \\ E-mail: jindal.shah@okstate.edu
}

\begin{abstract}
Molecular dynamics simulations are performed to probe the molecular-level interactions between various ionic pairs in the reciprocal mixture consisting of equimolar amounts of the cations 1-ethyl-3-methylimidazolium $\left[\mathrm{C}_{2} \mathrm{mim}\right]^{+}$and 1-n-hexyl-3-methylimidazolium $\left[\mathrm{C}_{6} \mathrm{mim}\right]^{+}$and dicyanamide $[\mathrm{DCA}]^{-}$and bis(trifluoromethanesulfonyl)imide $\left[\mathrm{NTf}_{2}\right]^{-}$anions. Any enhancement or depletion in these interactions is compared with those existing in equimolar binary mixtures $\left[\mathrm{C}_{2} \mathrm{mim}\right]\left[\mathrm{C}_{6} \mathrm{mim}\right][\mathrm{DCA}],\left[\mathrm{C}_{2} \mathrm{mim}\right]\left[\mathrm{C}_{6} \mathrm{mim}\right]\left[\mathrm{NTf}_{2}\right]$, $\left[\mathrm{C}_{2} \operatorname{mim}\right][\mathrm{DCA}]\left[\mathrm{NTf}_{2}\right]$, and $\left[\mathrm{C}_{6} \mathrm{mim}\right][\mathrm{DCA}]\left[\mathrm{NTf}_{2}\right]$ and pure ionic liquids $\left[\mathrm{C}_{2} \mathrm{mim}\right][\mathrm{DCA}]$, $\left[\mathrm{C}_{6} \mathrm{mim}\right][\mathrm{DCA}],\left[\mathrm{C}_{2} \mathrm{mim}\right]\left[\mathrm{NTf}_{2}\right]$, and $\left[\mathrm{C}_{6} \mathrm{mim}\right]\left[\mathrm{NTf}_{2}\right]$. The simulation results indicate that the $\left[\mathrm{C}_{2} \mathrm{mim}\right]^{+}$cation prefers to interact favorably with the strongly coordinating $[\mathrm{DCA}]^{-}$anion through enhanced hydrogen-bonding interactions, while showing no preferential interest towards the other anion in the reciprocal mixture. The average hydrogen bond lifetimes between $\left[\mathrm{C}_{2} \mathrm{mim}\right]^{+}$cation and $[\mathrm{DCA}]^{-}$anion increases by a factor of two in the reciprocal mixture compared to that in the pure system. We find that the hydrogen bond lifetimes in the various systems are directly correlated to the
\end{abstract}


first peak intensity in the center-of-mass radial distribution functions for corresponding ion pairs and have a direct bearing on the self-diffusion coefficients of the ions. Our results point to possibilities of tuning interactions between various species in reciprocal ionic liquid mixture by appropriately changing the cation and anion combinations.

\section{Introduction}

For more than two decades now, ionic liquids have gained widespread attraction because of several unique attributes such as low melting points despite ionic in nature, ability to exist as liquids at ambient conditions, low vapor pressures, and high thermal and chemical stability. In addition to these desirable properties, the ever-increasing attention paid to these ionic solvents is due to the fact that they offer the possibility of designing task-specific solvents with desired properties when an appropriate cation is paired with a suitable anion. Given that there exist seemingly an endless list of cations and a plethora of anions, it is no surprise that the chemical space for ionic liquids is vast. The search for an ideal ionic liquid with requisite properties can be expanded further by considering mixtures of two or more ionic liquids, which can potentially aid, for example, in improving sluggish dynamics encountered for many ionic liquids.

A large number of experimental and molecular simulation studies have extensively examined the molecular level interactions and structural transitions in ionic liquids mixtures and their relationship to deviations in macroscopic properties. ${ }^{1-4}$ Kapoor and Shah, in a recent study, showed that the difference in molar volumes of ionic liquids and hydrogen bonding accepting ability between the anions played a driving force in determining whether a given binary ionic liquid mixture with a common cation would exhibit non-ideal behavior. ${ }^{5}$ The authors conducted molecular dynamics (MD) simulation for 16 different binary anion mixtures and concluded that pure ionic liquids with molar volume difference greater than 60 $\mathrm{cm}^{3} / \mathrm{mol}$ and hydrogen bonding basicity difference greater than 0.4 when mixed would most 
likely yield non-native structural transitions at microscopic level. Such guidelines could serve to screen potential ionic liquid mixtures to identify non-ideal behavior. Several other binary ionic liquid mixtures with two anions and a common cation have obtained similar results where the difference in hydrogen bonding ability of the anions and the difference in anion size induces competition between the anions that causes the system to show non-ideal behavior. In such systems, the strongly coordinating anion prefers to occupy the locations proximal to the most acidic hydrogen in the imidazolium cation, which in turn displaces the less basic anion. ${ }^{6-9}$

As a consequence of the competition for the most acidic site in the imidazolium cation, binary anion mixtures also display hydrogen bond dynamics that differs from that in the pure ionic liquids. For example, the MD study by Wang et al. reported an enhancement in the hydrogen bond dynamics between 1-ethyl-3-methylimidazolium $\left[\mathrm{C}_{2} \mathrm{mim}\right]$ with tetrafluoroborate $\left[\mathrm{BF}_{4}\right]$ in the binary anion mixture containing $\left[\mathrm{C}_{2} \mathrm{mim}\right]^{+},\left[\mathrm{BF}_{4}\right]^{-}$and bis(trifluoromethanesulfonyl)imide $\left[\mathrm{NTf}_{2}\right]^{-} .{ }^{10}$ At $\left[\mathrm{C}_{2} \mathrm{mim}\right]\left[\mathrm{BF}_{4}\right]_{0.25}\left[\mathrm{NTf}_{2}\right]_{0.75}$ mole fraction the lifetime of intermittent hydrogen bond dynamics between $\left[\mathrm{C}_{2} \mathrm{mim}\right]\left[\mathrm{BF}_{4}\right]$ increases two-fold to 117 ps as compared to 57 ps for the pure $\left[\mathrm{C}_{2} \mathrm{mim}\right]\left[\mathrm{BF}_{4}\right]$ ionic liquid. Interestingly the hydrogen bonding lifetime of $\left[\mathrm{C}_{2} \operatorname{mim}\right]\left[\mathrm{NTf}_{2}\right]$ decreases as more $\left[\mathrm{BF}_{4}\right]^{-}$anion is added to the mixture. Similarly, Gekhre et al. in an MD study, examined the molecular level interaction and hydrogen bond dynamics between 1-butyl-3-methylimidazolium $\left[\mathrm{C}_{4} \mathrm{mim}\right]^{+}$and $\mathrm{Cl}^{-}$and trifluoromethanesulfonate [OTf $]^{-}{ }^{11}$ The authors observed an increase in the lifetime of hydrogen bond dynamics between $\left[\mathrm{C}_{4} \mathrm{mim}\right]$ and $\mathrm{Cl}$ as $\mathrm{Cl}^{-}$ion is added to the system, presumably due to the stronger hydrogen bonding ability of $\mathrm{Cl}^{-}$than that for $[\mathrm{OTF}]^{-}$anion.

Ionic liquids comprised of two cations and a common anion is another way to modulate properties of the resulting ionic liquid mixtures, primarily driven by the difference in the alkyl chain attached to the cations. ${ }^{12-14}$ Shimizu et al. reported, from an MD study, that 
the equimolar mixture of $\left[\mathrm{C}_{2} \mathrm{mim}\right]^{+}$and 1-hexyl-3-methylimidazolium $\left[\mathrm{C}_{6} \mathrm{mim}\right]^{+}$with $\left[\mathrm{NTf}_{2}\right]^{-}$ obeyed a nearly ideal mixing law with a small negative excess molar volume. ${ }^{15}$ In an experimental study, the Welton group found that the sign of the excess molar volume switches from negative to positive as the difference in the alkyl chain length between the imidazolium cation increases. The observation was attributed to the mismatch between the alkyl chain length leading to a large number of voids in the mixture ${ }^{16}$ as the longer alkyl chain is unable to incorporate the shorter chain into its non-polar domain, disrupting the continuous non-polar domain. ${ }^{17,18}$ Cosby et al., in a combined experimental MD simulation study, observed that the mesoscale morphologies in the mixtures of $\left[\mathrm{C}_{2} \mathrm{mim}\right]^{+}$and 1-octyl-3-methylimidazolium $\left[\mathrm{C}_{8} \mathrm{mim}\right]^{+}$with $\left[\mathrm{BF}_{4}\right]^{-}$could be tuned, which leads to an enhancement in the enhancement of static dielectric permittivity of the liquid by as much as $100 \%$ at equimolar concentrations as a result of change in the aggregation behavior of $\left[\mathrm{C}_{8} \mathrm{mim}\right]^{+} .{ }^{19}$ Such binary cation mixtures can also produce interesting hydrogen bonding dynamics as noted by Wang and co-workers in their MD study focusing on the mixtures of $\left[\mathrm{C}_{2} \mathrm{mim}\right]^{+}$and $\left[\mathrm{C}_{4} \mathrm{mim}\right]^{+}$cations with $\left[\mathrm{BF}_{4}\right]^{-} .{ }^{20}$ : the average lifetime for a hydrogen bond is greater for $\left[\mathrm{C}_{4} \mathrm{mim}\right]^{+-}\left[\mathrm{BF}_{4}\right]^{-}$ than that for $\left[\mathrm{C}_{2} \mathrm{mim}\right]^{+-}\left[\mathrm{BF}_{4}\right]^{-}$, which was reasoned to be partially responsible for the slow rotation of the $\left[\mathrm{C}_{4} \mathrm{mim}\right]^{+}$cation.

A yet-another approach to tailoring the physicochemical properties of ionic liquids is through reciprocal mixtures that contain at least two cations and two anions. ${ }^{21,22}$ These systems are interesting because they are usually formed by cations with varying alkyl chain lengths and anions that differ in their hydrogen bonding ability. By carefully selecting these parameters, which affect the non-polar and hydrogen bonding interactions, it may be possible to induce ionic associations that are not observable in neat or binary ionic liquid mixtures, leading to potentially non-ideal behavior. However, very few studies have probed molecular-level interactions in such mixtures. The experimental findings by Taige et al. indicate that the viscosity and ionic conductivity follow a non-ideal behavior for some reciprocal mixtures. ${ }^{23}$ 
Experiments by Bharmoia et al. also suggest that a pronounced deviation from ideality is possible for various physicochemical properties compared to other binary mixtures. ${ }^{24} \mathrm{An}$ MD examination of reciprocal mixtures of 1-benzyl-3-methylimidazolium $[\mathrm{Zmim}]^{+},\left[\mathrm{C}_{4} \mathrm{mim}\right]^{+}$, $\left[\mathrm{BF}_{4}\right]^{-}$, and $\left[\mathrm{NTf}_{2}\right]^{-}$revealed that the stronger hydrogen bonding ability anion $\left[\mathrm{BF}_{4}\right]^{-}$was seen to displace $\left[\mathrm{NTf}_{2}\right]^{-}$from the coordination shell of both the cations. ${ }^{25}$

To the best of our knowledge, there exists no study in which hydrogen bond dynamics of the reciprocal is systematically studied, especially when there is a mismatch in the alkyl chain length in the cationic species combined with a considerable difference in the hydrogen bond accepting ability of the anions. In such systems, it would be important to investigate how the presence of a cation capable of forming a continuous non-polar domain perturbs the distribution of anions in coordination shell of the cation with shorter alkyl chain, specifically the hydrogen bonding environment and hydrogen bonding dynamics as they exert profound influence on the physicochemical properties of ionic liquids. The focus of this work, therefore, is to employ an all-atom MD simulations to provide molecular-level insight into an equimolar reciprocal mixture that is composed of $\left[\mathrm{C}_{2} \mathrm{mim}\right]^{+},\left[\mathrm{C}_{6} \mathrm{mim}\right]^{+}$, dicyanamide $[\mathrm{DCA}]^{-}$ and $\left[\mathrm{NTf}_{2}\right]^{-}$. Following Kapoor and Shah, the cations and anions are selected as they offer a significant difference in molar volumes and the hydrogen bonding ability. We systematically evaluate structure and dynamics in pure ionic liquids, binary cation mixtures, binary anion mixtures, and the reciprocal mixture system. 

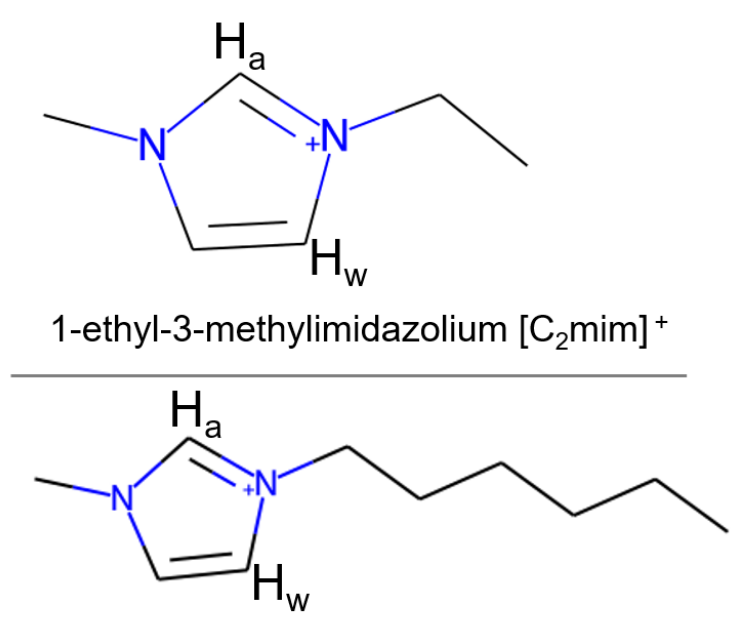

1-hexyl-3-methylimidazolium $\left[\mathrm{C}_{6} \mathrm{mim}\right]^{+}$

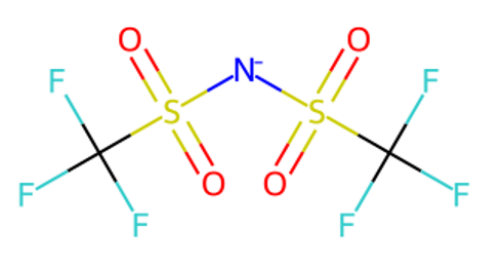

bis(trifluoromethanesulfonyl)imide $\left[\mathrm{NTf}_{2}\right]^{-}$

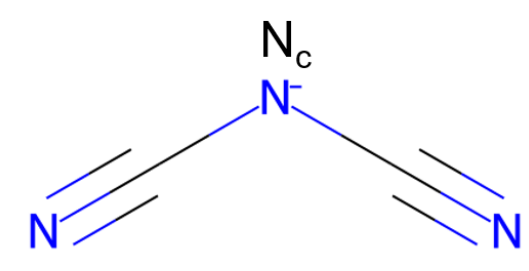

dicyanamide $[\mathrm{DCA}]^{-}$

Figure 1: Chemical structures of the cations and anions used in this study.

\section{Methodology}

\section{Force Fields}

The all-atom version of Optimized Potentials for Liquid simulations (OPLS-AA) forcefield was used to model the ionic liquids studied in this work. The forcefield for this study was taken from the work of Lopes and Paduá. ${ }^{26-28}$ The charge scaling for electrostatic interactions was set to \pm 0.8 to improve transport properties as demonstrated by other studies. ${ }^{29,30}$ We also conducted \pm 1.0 charge scaling simulation to compare the difference in results for bulk density and radial distribution function. The results for \pm 1.0 charge scaling are provided in the supporting information.

The OPLS-AA model treats each atom as an interaction site and the total potential energy $U_{\text {total }}$ takes into account bond stretching $U_{\text {Stretching, }}$, bond bending $U_{\text {Bending }}$, dihedral angle $U_{\text {Torsion, }}$ Coulomb, and 12-6 Leonard Jones (LJ) terms for non-bonded interactions 
$U_{\text {Non-Bonded. }}$ The functional form is shown below in Equations 1-5.

$$
\begin{gathered}
U_{\text {total }}=U_{\text {Non-Bonded }}+U_{\text {Stretching }}+U_{\text {Bending }}+U_{\text {Torsion }} \\
U_{\text {Non-Bonded }}=\sum_{i} \sum_{j} 4 \epsilon_{i j}\left[\left(\frac{\sigma_{i j}}{r_{i j}}\right)^{12}-\left(\frac{\sigma_{i j}}{r_{i j}}\right)^{6}\right]+\sum_{i} \sum_{j} \frac{q_{i} q_{j} e^{2}}{4 \pi \epsilon_{o} r_{i j}} \\
U_{\text {Stretching }}=\sum_{\text {Bonds }} \frac{K_{r}}{2}\left(r-r_{\text {eq }}\right)^{2} \\
U_{\text {Bending }}=\sum_{\text {Angles }} \frac{K_{\theta}}{2}\left(\theta-\theta_{\text {eq }}\right)^{2} \\
U_{\text {Torsion }}=\sum_{\text {Torsion }} \frac{V_{1}}{2}[1+\cos (\phi)]+\frac{V_{2}}{2}[1-\cos (2 \phi)]+\frac{V_{3}}{2}[1+\cos (3 \phi)]
\end{gathered}
$$

where LJ parameters $\sigma_{i j}$ and $\epsilon_{i j}$ represent the energy and size parameters, $r_{i j}$ denotes the distance between atomic sites $i$ and $j, q$ is the partial atomic charge for electrostatic interactions. $r, r_{e q}, \theta, \theta_{e q}$ are bond length, equilibrium bond length, bending angle and equilibrium bending angle, respectively. $K_{r}, K_{\theta}$ are force constant for stretching and bending, respectively; $V_{i}$ is the torsional parameters for dihedrals. LJ potential between unlike pairs was calculated using the geometric combining rule for $\sigma$ and $\epsilon$. The intramolecular non-bonded interactions between atoms separated by three bonds was evaluated using a scaling factor of 0.5 for both the LJ and electrostatic interactions.

\section{Simulation Details}

Molecular Dynamic (MD) simulations were performed for nine different systems at $323.0 \mathrm{~K}$ using Gromacs 2018 software package ${ }^{31,32}$ including four pure ionic liquid systems [ $\left.\mathrm{C}_{2} \mathrm{mim}\right][\mathrm{DCA}]$, $\left[\mathrm{C}_{2} \min \right]\left[\mathrm{NTf}_{2}\right],\left[\mathrm{C}_{6} \mathrm{mim}\right][\mathrm{DCA}],\left[\mathrm{C}_{6} \mathrm{mim}\right]\left[\mathrm{NTf}_{2}\right]$, four binary ionic liquid systems with equimolar compositions $\left[\mathrm{C}_{2} \operatorname{mim}\right][\mathrm{DCA}]_{0.5}\left[\mathrm{NTf}_{2}\right]_{0.5},\left[\mathrm{C}_{6} \mathrm{mim}\right][\mathrm{DCA}]_{0.5}\left[\mathrm{NTf}_{2}\right]_{0.5},\left[\mathrm{C}_{2} \mathrm{mim}\right]_{0.5}\left[\mathrm{C}_{6} \operatorname{mim}\right]_{0.5}[\mathrm{DCA}]$, $\left[\mathrm{C}_{2} \mathrm{mim}\right]_{0.5}\left[\mathrm{C}_{6} \mathrm{mim}\right]_{0.5}\left[\mathrm{NTf}_{2}\right]$, and an equimolar reciprocal system $\left[\mathrm{C}_{2} \mathrm{mim}\right]_{0.5}\left[\mathrm{C}_{6} \mathrm{mim}\right]_{0.5}[\mathrm{DCA}]_{0.5}\left[\mathrm{NTf}_{2}\right]_{0.5}$. A cubic simulation box was employed for each of the ionic liquid systems. The length of 
the simulation box for pure systems was estimated from experimental density at $323 \mathrm{~K}$, while the simulation box length for the binary mixtures was set assuming ideal mixing behavior. Similarly, the initial volume for the reciprocal system was calculated by considering the ideal mixing volume for the ionic liquids $\left[\mathrm{C}_{2} \mathrm{mim}\right][\mathrm{DCA}],\left[\mathrm{C}_{2} \mathrm{mim}\right]\left[\mathrm{NTf}_{2}\right],\left[\mathrm{C}_{6} \mathrm{mim}\right][\mathrm{DCA}]$, and $\left[\mathrm{C}_{6} \mathrm{mim}\right]\left[\mathrm{NTf}_{2}\right]$ with mole fractions of each of the ionic liquids set to 0.25 . Packmol was used to prepare an initial configuration for all the systems for 500 ion pairs ${ }^{33}$ with periodic boundary conditions applied in all directions.

The simulation protocol involved five steps: minimization, annealing, NVT equilibration, and NPT equilibration followed by two production runs in the NPT ensemble. Each system was first minimized using the steepest-descent algorithm for 10000 steps and subjected to a $1.5 \mathrm{~ns}$ annealing protocol. The temperature was slowly increased to $323 \mathrm{~K}$ during the first stage of annealing followed by relaxation of the system at $323 \mathrm{~K}$. The temperature was further raised to $523 \mathrm{~K}$ to ensure additional relaxation of the system before bringing the system down to $323 \mathrm{~K}$. An NVT equilibration for 10 ns was performed next, in which the temperature of the system was controlled at $323 \mathrm{~K}$ using a Berendsen thermostat with a time constant of 0.4 ps. An NPT equilibration for 10 ns was carried out so that the density approached an equilibrium value; Berendsen thermostat and barostat were applied during this stage with time constants of $0.4 \mathrm{ps}$ and $0.2 \mathrm{ps}$, respectively. The first NPT production run lasted 60 ns in which the Nosé-Hoover thermostat ${ }^{34}$ and Parrinello-Rahman barostat ${ }^{35}$ were activated at a coupling constant of $\tau_{\mathrm{t}}=0.4 \mathrm{ps}$ and $\tau_{\mathrm{p}}=2.0 \mathrm{ps}$. Finally data collection and analysis were carried out on the final 20 ns of the NPT production run. Results for each system were averaged over three independent simulations with different starting initial coordinates to estimate the uncertainty in property predictions.

During the course of the entire simulation protocol, the bonds involving hydrogen atoms were constrained using the LINCS algorithm. Both LJ and electrostatic interactions were 
truncated at $12 \AA$, while long-range electrostatic interactions were handled using particlemesh Ewald (PME) summation with a PME order of 4 and Fourier spacing of $0.1 \mathrm{~nm}$. Long-range corrections were also applied for LJ energy and pressure.

\section{Results and discussion}

\section{Liquid Densities}

The densities of all the nine different systems studied in this paper are shown in Table 1 and visualized in Figure S1. The simulated densities of the pure systems with both charge scaling of \pm 1.0 and \pm 0.8 are compared with experimental data. Density data for the \pm 1.0 charge scaling are provided in the supporting information. The pure ionic liquid densities obtained with \pm 1.0 scaling are in excellent agreement with experimental measurement as indicated by the average absolute relative deviation (AARD) of $1.46 \%$. In contrast, the AARD increases to $5.2 \%$ for pure ionic liquid densities with \pm 0.8 charge scaling. ${ }^{29,36,37}$ The deviations in densities are similar in magnitude to Goloviznina et al. study with \pm 0.8 scaling using CL\&P forcefields. ${ }^{29}$

Table 1: Detailed description of the system composition and equilibrium densities at $323 \mathrm{~K}$

\begin{tabular}{|c|c|c|c|c|c|}
\hline \multirow[t]{2}{*}{ System } & \multicolumn{4}{|c|}{ Ions } & \multirow{2}{*}{$\begin{array}{l}\begin{array}{l}\text { Density } \\
\left(\mathrm{g} / \mathrm{cm}^{3}\right)\end{array} \\
\text { This work }\end{array}$} \\
\hline & {$\left[\mathrm{C}_{2} \mathrm{mim}\right]^{+}$} & {$\left[\mathrm{C}_{6} \mathrm{mim}\right]^{+}$} & {$[\mathrm{DCA}]^{-}$} & {$\left[\mathrm{NTf}_{2}\right]^{-}$} & \\
\hline$\left[\mathrm{C}_{2} \mathrm{mim}\right][\mathrm{DCA}]$ & 500 & & 500 & & $1.026 \pm 0.001$ \\
\hline$\left[\mathrm{C}_{2} \mathrm{mim}\right]\left[\mathrm{NTf}_{2}\right]$ & 500 & & & 500 & $1.486 \pm 0.009$ \\
\hline$\left[\mathrm{C}_{6} \mathrm{mim}\right][\mathrm{DCA}]$ & & 500 & 500 & & $0.974 \pm 0.001$ \\
\hline$\left[\mathrm{C}_{6} \mathrm{mim}\right]\left[\mathrm{NTf}_{2}\right]$ & & 500 & & 500 & $1.332 \pm 0.008$ \\
\hline$\left[\mathrm{C}_{2} \mathrm{mim}\right]\left[\mathrm{C}_{6} \mathrm{mim}\right][\mathrm{DCA}]$ & 250 & 250 & 500 & & $0.996 \pm 0.001$ \\
\hline$\left[\mathrm{C}_{2} \mathrm{mim}\right]\left[\mathrm{C}_{6} \mathrm{mim}\right]\left[\mathrm{NTf}_{2}\right]$ & 250 & 250 & & 500 & $1.390 \pm 0.009$ \\
\hline$\left[\mathrm{C}_{2} \mathrm{mim}\right][\mathrm{DCA}]\left[\mathrm{NTf}_{2}\right]$ & 500 & & 250 & 250 & $1.292 \pm 0.001$ \\
\hline$\left[\mathrm{C}_{6} \mathrm{mim}\right][\mathrm{DCA}]\left[\mathrm{NTf}_{2}\right]$ & & 500 & 250 & 250 & $1.184 \pm 0.001$ \\
\hline$\left[\mathrm{C}_{2} \mathrm{mim}\right]\left[\mathrm{C}_{6} \mathrm{mim}\right][\mathrm{DCA}]\left[\mathrm{NTf}_{2}\right.$ & $\left.\mathrm{f}_{2}\right] 250$ & 250 & 250 & 250 & $1.231 \pm 0.001$ \\
\hline
\end{tabular}




\section{Radial Distribution Function (RDF)}

To understand the molecular-level structure between the ions in the reciprocal mixture, we computed the center of mass $(\mathrm{COM})$ radial distribution function (RDF) plot for all the cation-anion interactions in the system as depicted in Figure 2(a). It was observed that the characteristic of the first solvation shell as deduced from the intensity of the first peak and the distance at which the peak is located varied with the system. For example, the cation-anion correlations are strongest for the $\left[\mathrm{C}_{2} \mathrm{mim}\right]-[\mathrm{DCA}]$ as the intensity of the first peak in the RDF is highest amongst all the RDFs. In contrast, the first peak height is nearly identical for $\left[\mathrm{C}_{6} \mathrm{mim}\right][\mathrm{DCA}],\left[\mathrm{C}_{2} \mathrm{mim}\right]\left[\mathrm{NTf}_{2}\right]$, and $\left[\mathrm{C}_{6} \operatorname{mim}\right]\left[\mathrm{NTf}_{2}\right]$. The observation points to a strong preferential interaction between the $\left[\mathrm{C}_{2} \mathrm{mim}\right]-[\mathrm{DCA}]$. This is also reflected by the greater number of $[\mathrm{DCA}]^{-}$surrounding $\left[\mathrm{C}_{2} \mathrm{mim}\right]^{+}$in the coordination number plot in Figure 2(b). This is most likely due to the easier access to the hydrogen bonding sites of $\left[\mathrm{C}_{2} \mathrm{mim}\right]^{+}$by the stronger coordinating ability and smaller size of $[\mathrm{DCA}]^{-}$in comparison

to those for $\left[\mathrm{NTf}_{2}\right]^{-}$. The location of the first peak height is almost invariant at $\sim 5 \AA$ for the cation-anion interactions in $\left[\mathrm{C}_{2} \mathrm{mim}\right][\mathrm{DCA}],\left[\mathrm{C}_{6} \mathrm{mim}\right][\mathrm{DCA}]$, and $\left[\mathrm{C}_{2} \operatorname{mim}\right]\left[\mathrm{NTf}_{2}\right]$, while the bulky nature of both the ions in $\left[\mathrm{C}_{6} \operatorname{mim}\right]\left[\mathrm{NTf}_{2}\right]$ leads to the first peak height locating further by $0.5 \AA$. The anion size difference also affects the location of the first minimum in the RDFs such that the first solvation shell of $[D C A]^{-}$around the cations is more contracted than that of $\left[\mathrm{NTf}_{2}\right]^{-}$. The location of the first minimum remains unaffected for a given anion, which suggests that the size of the first solvation shell is determined primarily by the interaction of the imidazolium ring with the anion. The type of cation-anion pair also exert subtle changes in the second solvation shell: the peak intensity is nearly identical for the pairs involving $\left[\mathrm{C}_{2} \mathrm{mim}\right]^{+}$and is higher than those for pairs containing $\left[\mathrm{C}_{6} \mathrm{mim}\right]^{+}$. Beyond the second shell, the RDFs are nearly identical in all respects. 

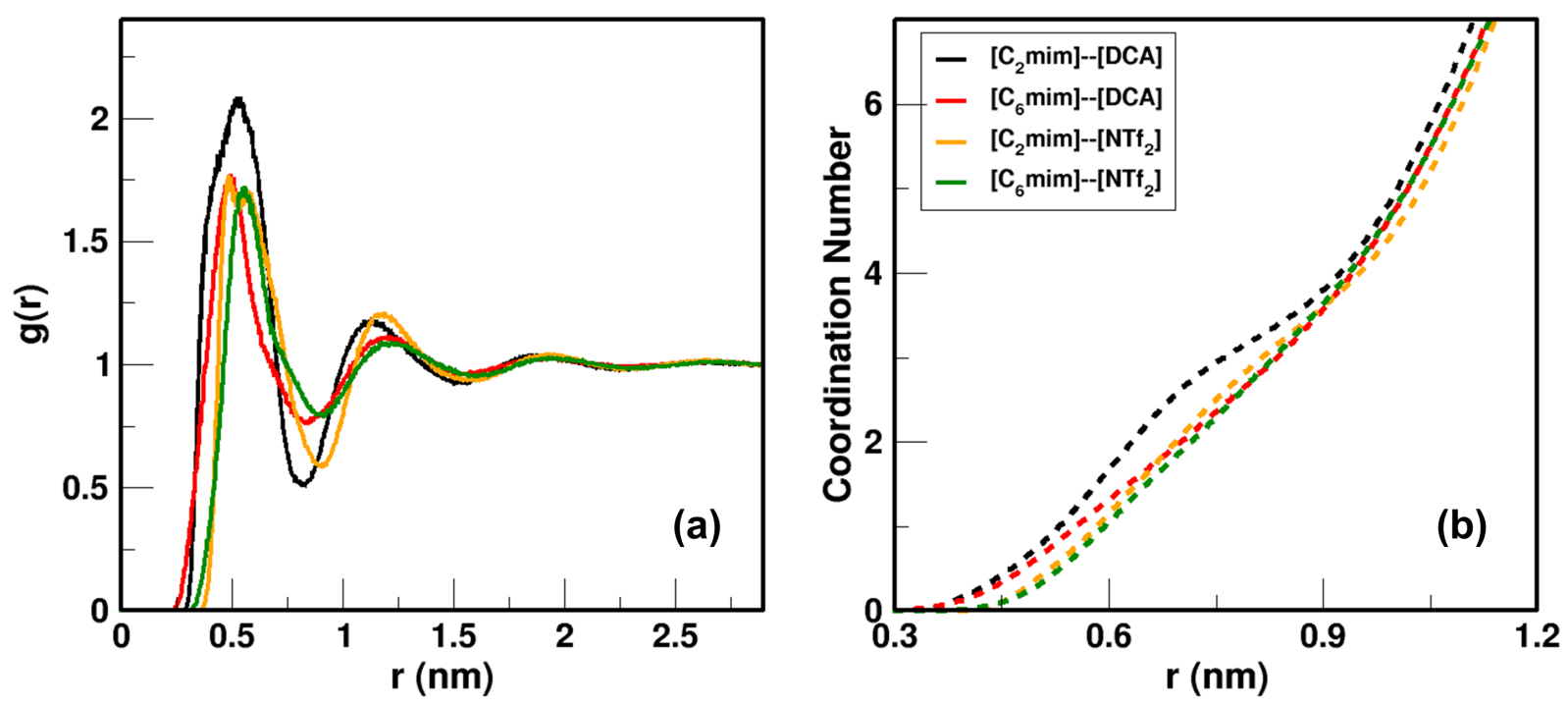

Figure 2: Center of mass (COM) radial distribution plot of all the cation-anion interactions in reciprocal mixture.

Next we determined the cation-anion COM radial distribution functions for $\left[\mathrm{C}_{2} \mathrm{mim}\right][\mathrm{DCA}]$ in various ionic liquid mixtures to examine whether the preferential interaction of [DCA $]^{-}$ with $\left[\mathrm{C}_{2} \mathrm{mim}\right]^{+}$is retained. Examination of these correlations in Figure 3 reveals that the first peak height follows the order $\left[\mathrm{C}_{2} \mathrm{mim}\right][\mathrm{DCA}]<\left[\mathrm{C}_{2} \mathrm{mim}\right]_{0.5}\left[\mathrm{C}_{6} \mathrm{mim}\right]_{0.5}[\mathrm{DCA}]<\left[\mathrm{C}_{2} \mathrm{mim}\right][\mathrm{DCA}]_{0.5}\left[\mathrm{NTf}_{2}\right]_{0.5}$ $<\left[\mathrm{C}_{2} \mathrm{mim}\right]_{0.5}\left[\mathrm{C}_{6} \mathrm{mim}_{0.5}[\mathrm{DCA}]_{0.5}\left[\mathrm{NTf}_{2}\right]_{0.5}\right.$, which clearly shows that the $\left[\mathrm{C}_{2} \mathrm{mim}\right]-[\mathrm{DCA}]$ interactions become stronger in binary and reciprocal mixtures. The minor increase in the peak height when $\left[\mathrm{C}_{6} \mathrm{mim}\right]$ is added to $\left[\mathrm{C}_{2} \mathrm{mim}\right][\mathrm{DCA}]$ is attributed to the formation of nonpolar domains due to the presence of $\left[\mathrm{C}_{6} \mathrm{mim}\right]^{+}$, which leads to the confinement of the anion in the polar region and has an effect of pushing the anion closer to $\left[\mathrm{C}_{2} \mathrm{mim}\right]^{+}$. Shimizu et al. reported a similar increase in first peak height in the RDF between the carbon attached to $\mathrm{H}_{\mathrm{a}}$ and oxygen atom in $\left[\mathrm{NTf}_{2}\right]^{-}$an equimolar mixture of $\left[\mathrm{NTf}_{2}\right]^{-}$an ef $\left[\mathrm{C}_{2} \mathrm{mim}\right]\left[\mathrm{NTf}_{2}\right]$ and $\left[\mathrm{C}_{6} \mathrm{mim}\right]\left[\mathrm{NTf}_{2}\right] .{ }^{15} \mathrm{~A}$ more pronounced influence on the first peak height is noted when a weakly coordinating anion $\left[\mathrm{NTf}_{2}\right]^{-}$is mixed with $\left[\mathrm{C}_{2} \mathrm{mim}\right][\mathrm{DCA}]$, which is consistent with several reports in literature that the anion with stronger hydrogen bonding ability preferentially interacts with a cation in ionic liquid mixtures containing a common cation and two anions. Lastly, the reciprocal mixture shows the highest peak height compared to all the 
other systems exhibiting a combined influence of the larger cation and a weakly coordinating anion in driving the preferential interaction between $\left[\mathrm{C}_{2} \mathrm{mim}\right]^{+}$and $[\mathrm{DCA}]^{-}$. The trends seen for the reciprocal mixture are similar to a recent MD study by Sappidi et al. ${ }^{25}$ where the authors found that the $\left[\mathrm{BF}_{4}\right]^{-}$anion tend to show a strong association for the two cations in the reciprocal mixture compared to $\left[\mathrm{NTf}_{2}\right]^{-}$anion.

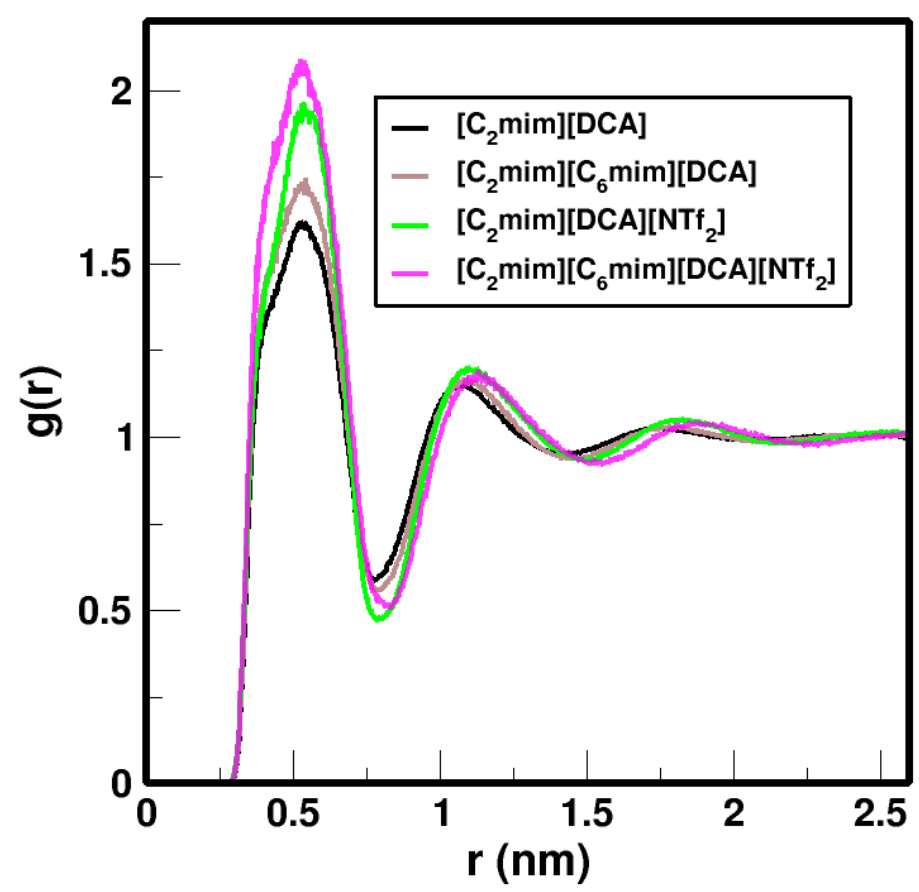

Figure 3: COM RDF plot for $\left[\mathrm{C}_{2} \mathrm{mim}\right]--[\mathrm{DCA}]$ interactions in pure and various mixtures.

The origin of the preferential interaction between $\left[\mathrm{C}_{2} \mathrm{mim}\right]^{+}$and $[\mathrm{DCA}]^{-}$in mixtures relative to the pure ionic liquid is examined further using the radial distribution functions around the hydrogen bonding sites in the imidazolium ring. Figure 4(a) depicts the interactions between $\mathrm{H}_{\mathrm{a}}$ position in the cation with the $\mathrm{N}_{c}$ position in the $[\mathrm{DCA}]^{-}$anion as one of the dominant hydrogen bonding sites (please refer to Figure 1 for the nomenclature). The magnitude of the first peak intensity greater than 1 at short distances for all the systems indicate a presence of hydrogen bonding interactions. The RDF's exhibit split peaks in the 
first solvation shell, suggesting that $[\mathrm{DCA}]^{-}$interacts with the hydrogen bonding site through multiple conformations. It is interesting to note that the two peaks in the first solvation shell for all the systems occur at around the same distance, while a clear change in the peak heights is observed for pure and mixture systems. The neat ionic liquid $\left[\mathrm{C}_{2} \mathrm{mim}\right][\mathrm{DCA}]$ exhibits the lowest peak height, which is enhanced upon the addition of the $\left[\mathrm{C}_{6} \mathrm{mim}\right]^{+}$cation. The addition of $\left[\mathrm{NTf}_{2}\right]^{-}$induces a significant increase in the first peak height. Such a behavior, brought about the difference in the hydrogen bonding ability of the two anions, is well documented in literature. ${ }^{5,38}$ Finally, the reciprocal mixture shows the largest increase in the peak height amongst all the mixture systems, demonstrating the combined effect of the difference in the hydrogen bonding ability of the anions and the formation of non-polar domains due to the $\left[\mathrm{C}_{6} \mathrm{mim}\right]^{+}$cation. The RDF's for the $\mathrm{H}_{w}$ position position in the cation and the $[\mathrm{DCA}]^{-}$anion are provided in Figure 4(b). Although the first peak intensities are lower than those found for the $\mathrm{H}_{a}$ site, the ranking of peak heights is similar to that obtained for the most acidic hydrogen bonding site, which clearly shows that enhanced interactions of $\left[\mathrm{C}_{2} \mathrm{mim}\right]^{+}$with $[\mathrm{DCA}]^{-}$in ionic liquid mixture systems are due to an increased coordination of $[\mathrm{DCA}]^{-}$at all the hydrogen bonding sites. Overall, these findings confirm that the preferential interaction of the anion with stronger hydrogen bonding ability can be dramatically enhanced by forming ionic liquid mixtures. As hydrogen bonding interactions have been implicated in several physicochemical properties of ionic liquids, it is expected that ionic liquids properties can be tuned through a subtle manipulation of these interactions through various combinations of cations and anions in an ionic liquid mixture. 

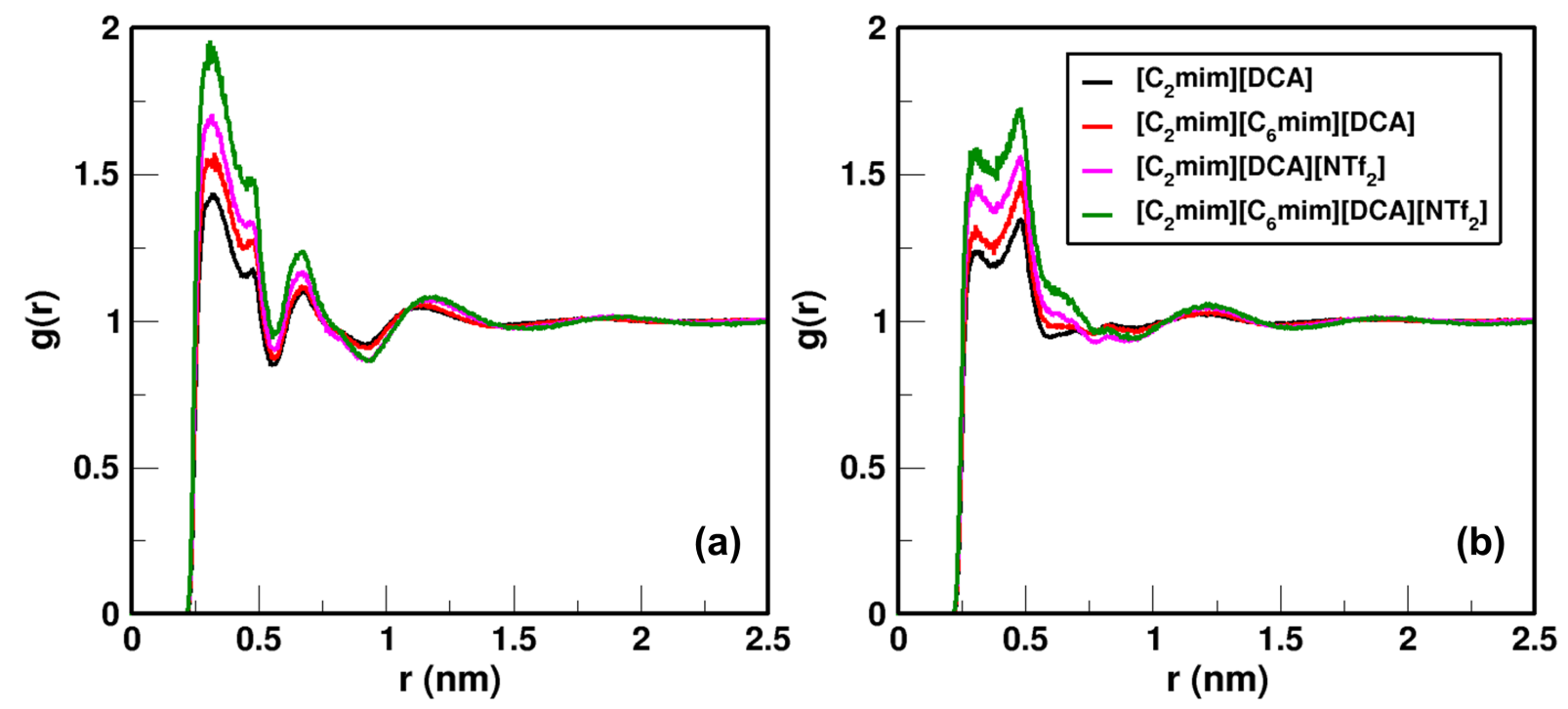

Figure 4: RDF plots for site-site interaction in pure and various mixtures. (a) $\mathrm{H}_{a}--\mathrm{N}_{c}$ site-site interactions between $\left[\mathrm{C}_{2} \mathrm{mim}\right]--[\mathrm{DCA}]$. (b) $\mathrm{H}_{w}--\mathrm{N}_{c}$ site-site interaction between $\left[\mathrm{C}_{2} \mathrm{mim}\right]--[\mathrm{DCA}]$.

We also analyzed the hydrogen bonding interactions between the most negatively charged oxygen atom in $\left[\mathrm{NTf}_{2}\right]^{-}$and the $\mathrm{H}_{a}$ and $\mathrm{H}_{w}$ sites in the $\left[\mathrm{C}_{2} \mathrm{mim}\right]^{+}$cation. The radial distributions functions for the $\mathrm{H}_{a}$ site are shown in Figure 5, which reveal that the ordering of the first peak intensity for the various systems is dependent on the type of the mixture under consideration. As seen for the hydrogen bonding interaction of $[\mathrm{DCA}]^{-}$with $\mathrm{H}_{a}$, there is a rise in the intensity when a longer alkyl chain cation is added to the system. However, the ionic liquid mixture in which $[\mathrm{DCA}]^{-}$is present, there is depression in the first peak intensity in the $\mathrm{RDF}$ of $\mathrm{H}_{a}$ with $\mathrm{O}$ relative to that for the pure system. This is in direct contrast to the behavior observed in the RDF of $\mathrm{H}_{a}$ with $\mathrm{N}_{c}$ of $[\mathrm{DCA}]^{-}$, confirming the preferential interaction of $[\mathrm{DCA}]^{-}$with the hydrogen bonding site. The first peak height is elevated when the reciprocal mixture is analyzed; however, the magnitude is still smaller than that obtained in the pure system. The RDF's between $\mathrm{H}_{w}$ and $\mathrm{O}$ mirror the trends for the $\mathrm{H}_{a}$ and O RDF's with a decrease in the first peak height for respective systems. 

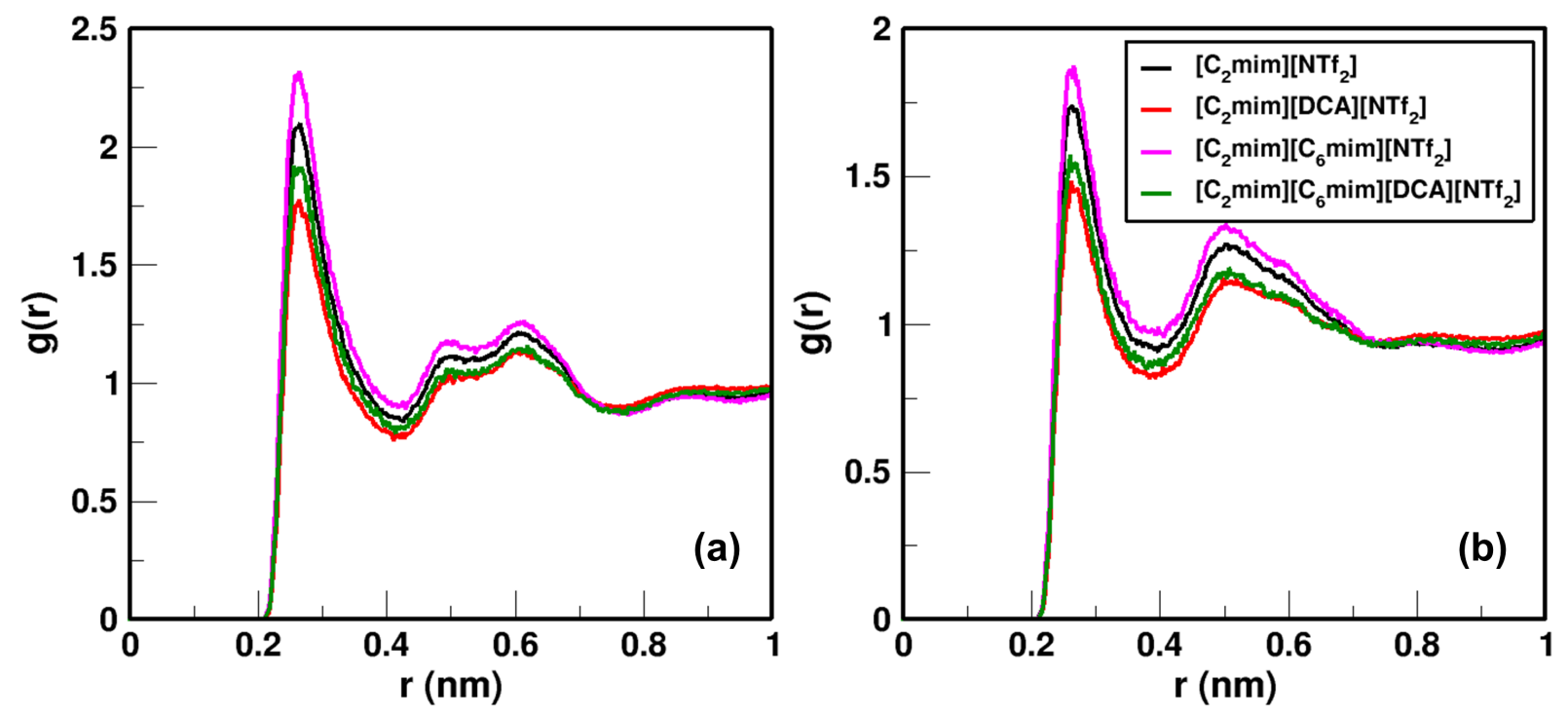

Figure 5: RDF plots for site-site interaction in pure and various mixtures. (a) $\mathrm{H}_{a}--\mathrm{O}$ site-site interactions between $\left[\mathrm{C}_{2} \mathrm{mim}\right]-\left[\mathrm{NTf}_{2}\right]$. (b) $\mathrm{H}_{w}--\mathrm{O}$ site-site interaction between $\left[\mathrm{C}_{2} \mathrm{mim}\right]-\left[\mathrm{NTf}_{2}\right]$.

\section{Hydrogen Bonding Lifetimes}

To understand how this enhancement in interaction for the hydrogen bonding sites affects the dynamics of the system, the lifetime of hydrogen bond dynamics between the ion pairs for all the systems were calculated using the intermittent hydrogen bonding autocorrelation function (Eq. 6) calculated over the first 1 ns of the second NPT production run using TRAVIS $^{39}$

$$
C(t)=\frac{<h(0) h(t)>}{<h(0)>}
$$

where $\mathrm{h}(\mathrm{t})$ takes a value of 1 if the hydrogen bond is persistent, but assumes a value of 0 when the hydrogen bond is broken. We defined the hydrogen bond following the criteria laid out in the work by Kirchner et al. ${ }^{30,40}$. The cutoff angle between donor-acceptor-hydrogen was set to $30^{\circ}$, the cutoff distance between the acceptor-donor was set at the distance corresponding to the first minimum in the center of mass RDF between the cation-anion, and the cut-off distance for the acceptor-hydrogen atom was limited to the first solvation shell 
of the hydrogen bonding sites. Further details are provided in the supporting information (Figure S9, S10, S11, S12). The autocorrelation was calculated for the $\mathrm{C}_{a}-\mathrm{H}_{a}-\mathrm{N}_{c}$ and $\mathrm{C}_{a}-\mathrm{H}_{a^{-}} \mathrm{O}$ interactions, where $\mathrm{C}_{a}$ and $\mathrm{H}_{a}$ atom belongs to $\left[\mathrm{C}_{2} \mathrm{mim}\right]^{+} /\left[\mathrm{C}_{6} \mathrm{mim}\right]^{+}$cation, $\mathrm{N}_{c}$ is the central nitrogen atom in $[\mathrm{DCA}]^{-}$anion and $\mathrm{O}$ is the oxygen atom in the $\left[\mathrm{NTf}_{2}\right]^{-}$anion.

The average hydrogen bonding lifetime between a given pair of atoms was calculated by integrating the hydrogen bonding autocorrelation function

$$
\tau_{l t}=\int_{0}^{\infty} C(t) d t
$$

This integral was evaluated analytically by fitting a stretched exponential equation

$$
C(t)=a_{1} e^{-t / b_{1}}+a_{2} e^{-t / b_{2}}+a_{3} e^{-t / b_{3}}
$$

where, $a_{3}=1-a_{1}-a_{2}$ yielding

$$
\tau_{l t}=a_{1} b_{1}+a_{2} b_{2}+a_{3} b_{3}
$$

The hydrogen bonding lifetime values obtained from the analysis are included in Table 2.

Table 2: Average lifetime $\tau_{l t}$ of hydrogen bonds. $\mathrm{C}_{a 2}$ and $\mathrm{H}_{a 2}$ atom are attached to the

\begin{tabular}{|c|c|c|c|c|}
\hline System & $\overline{\mathrm{J}_{a 2}--\mathrm{H}_{a 2}--\mathrm{N}_{c}}$ & $\mathrm{C}_{a 2}--\mathrm{H}_{a 2}--\mathrm{O}$ & $\mathrm{C}_{a 6}--\mathrm{H}_{a 6}--\mathrm{N}_{c}$ & $\mathrm{C}_{a 6}--\mathrm{H}_{a 6}--\mathrm{O}$ \\
\hline$\left[\mathrm{C}_{2} \mathrm{mim}\right][\mathrm{DCA}]$ & $42.2 \pm 5.7$ & & & \\
\hline$\left[\mathrm{C}_{2} \operatorname{mim}\right]\left[\mathrm{NTf}_{2}\right]$ & & $29.2 \pm 1.5$ & & \\
\hline$\left[\mathrm{C}_{6} \mathrm{mim}\right][\mathrm{DCA}]$ & & & $88.7 \pm 6.1$ & \\
\hline$\left[\mathrm{C}_{6} \operatorname{mim}\right]\left[\mathrm{NTf}_{2}\right]$ & & & & $50.1 \pm 6.4$ \\
\hline$\left[\mathrm{C}_{2} \mathrm{mim}\right]\left[\mathrm{C}_{6} \mathrm{mim}\right][\mathrm{DCA}]$ & $57.6 \pm 10.2$ & & $66.9 \pm 0.3$ & \\
\hline$\left[\mathrm{C}_{2} \mathrm{mim}\right]\left[\mathrm{C}_{6} \mathrm{mim}\right]\left[\mathrm{NTf}_{2}\right]$ & & $38.8 \pm 7.7$ & & $37.3 \pm 0.9$ \\
\hline$\left[\mathrm{C}_{2} \mathrm{mim}\right][\mathrm{DCA}]\left[\mathrm{NTf}_{2}\right]$ & $55.9 \pm 5.3$ & $26.5 \pm 3.5$ & & \\
\hline$\left[\mathrm{C}_{6} \mathrm{mim}\right][\mathrm{DCA}]\left[\mathrm{NTf}_{2}\right]$ & & & $109.4 \pm 3.6$ & $49.6 \pm 4.4$ \\
\hline$\left[\mathrm{C}_{2} \mathrm{mim}\right]\left[\mathrm{C}_{6} \mathrm{mim}\right][\mathrm{DCA}]\left[\mathrm{NTf}_{2}\right]$ & $73.9 \pm 11.9$ & $34.6 \pm 4.9$ & $95.1 \pm 16.8$ & $37.9 \pm 2.5$ \\
\hline
\end{tabular}
$\left[\mathrm{C}_{2} \mathrm{mim}\right]^{+}$cation, $\mathrm{C}_{a 6}$ and $\mathrm{H}_{a 6}$ atom are attached to the $\left[\mathrm{C}_{6} \mathrm{mim}\right]^{+}$cation, $\mathrm{N}_{c}$ is attached to the $[\mathrm{DCA}]^{-}$anion and $\mathrm{O}$ is attached to the $\left[\mathrm{NTf}_{2}\right]^{-}$anion. 
For the pure ionic liquids, we observe an increase in the hydrogen bonding lifetime as the alkyl chain in the imidazolium cation is elongated for a given anion, attributable to the formation of the non-polar domain confining the movement of the anion to the polar domain. The trend is in similar agreement with the work of Kircher et al. ${ }^{40}$ where the authors found the hydrogen bonding lifetime for the same hydrogen bonding sites of $\left[\mathrm{C}_{4} \mathrm{mim}\right]\left[\mathrm{NTf}_{2}\right]$ at 323.0 $\mathrm{K}$ using CL\&P forcefields to be $35.4 \mathrm{ps}$ which is in between the lifetime of $\left[\mathrm{C}_{2} \mathrm{mim}\right]\left[\mathrm{NTf}_{2}\right]$ and $\left[\mathrm{C}_{6} \mathrm{mim}\right]\left[\mathrm{NTf}_{2}\right]$ as seen from the table. Reddy et al. saw a similar trend in the hydrogen bonding lifetime where it increased by a factor of 14 as the alkyl length of the primary ammonium cation paired with formate anion increased from methyl chain to propyl chain. ${ }^{41}$

The increase in the lifetime for hydrogen bonding interaction is primarily dominated by the identity of the anion. For instance. the ratio of the average lifetime for $\left[\mathrm{C}_{6} \mathrm{mim}\right][\mathrm{DCA}]$ is $\sim 2$ times the lifetime of $\left[\mathrm{C}_{2} \mathrm{mim}\right][\mathrm{DCA}]$, while the ratio drops to $\sim 1.7$ in going from $\left[\mathrm{C}_{2} \operatorname{mim}\right]\left[\mathrm{NTf}_{2}\right]$ to $\left[\mathrm{C}_{6} \mathrm{mim}\right]\left[\mathrm{NTf}_{2}\right]$. The hydrogen bonding lifetime ratio is also similar to the change in viscosity for a given ionic liquid series. Experimental viscosity of $\left[\mathrm{C}_{2} \mathrm{mim}\right][\mathrm{DCA}]^{42}$ at $323.15 \mathrm{~K}$ is found to $8.51 \mathrm{cp}$ compared to $18.72 \mathrm{cp}$ for $\left[\mathrm{C}_{6} \mathrm{mim}\right][\mathrm{DCA}]^{43}$ which is roughly 2.20 times the increase in viscosity as the alkyl chain length of the cation is increased. Similarly, the viscosity of $\left[\mathrm{C}_{2} \operatorname{mim}\right]\left[\mathrm{NTf}_{2}\right]^{44}$ at $323.15 \mathrm{~K}$ which is $15.61 \mathrm{cp}$ that only increases to $26.25 \mathrm{cp}$ for $\left[\mathrm{C}_{6} \mathrm{mim}\right]\left[\mathrm{NTf}_{2}\right]^{45}$ which is roughly a factor of 1.68 almost identical to the ratio of the hydrogen bonding lifetime for these systems. Our results are consistent with the findings by Zhang and Maginn that the transport properties such as self-diffusion coefficients and the ionic conductivity are inversely related to the ion-pair correlation timescales. ${ }^{46}$ For mixtures, we notice that the hydrogen bonding lifetimes increase in accordance to the increase in the height of the RDF's between $\mathrm{H}_{a}$ and $\mathrm{N}_{c}$ for $\left[\mathrm{C}_{2} \operatorname{mim}\right][\mathrm{DCA}]$ and $\mathrm{H}_{a}$ and $\mathrm{O}$ for $\left[\mathrm{C}_{2} \operatorname{mim}\right]\left[\mathrm{NTf}_{2}\right]$ as illustrated in Figure 6 . 

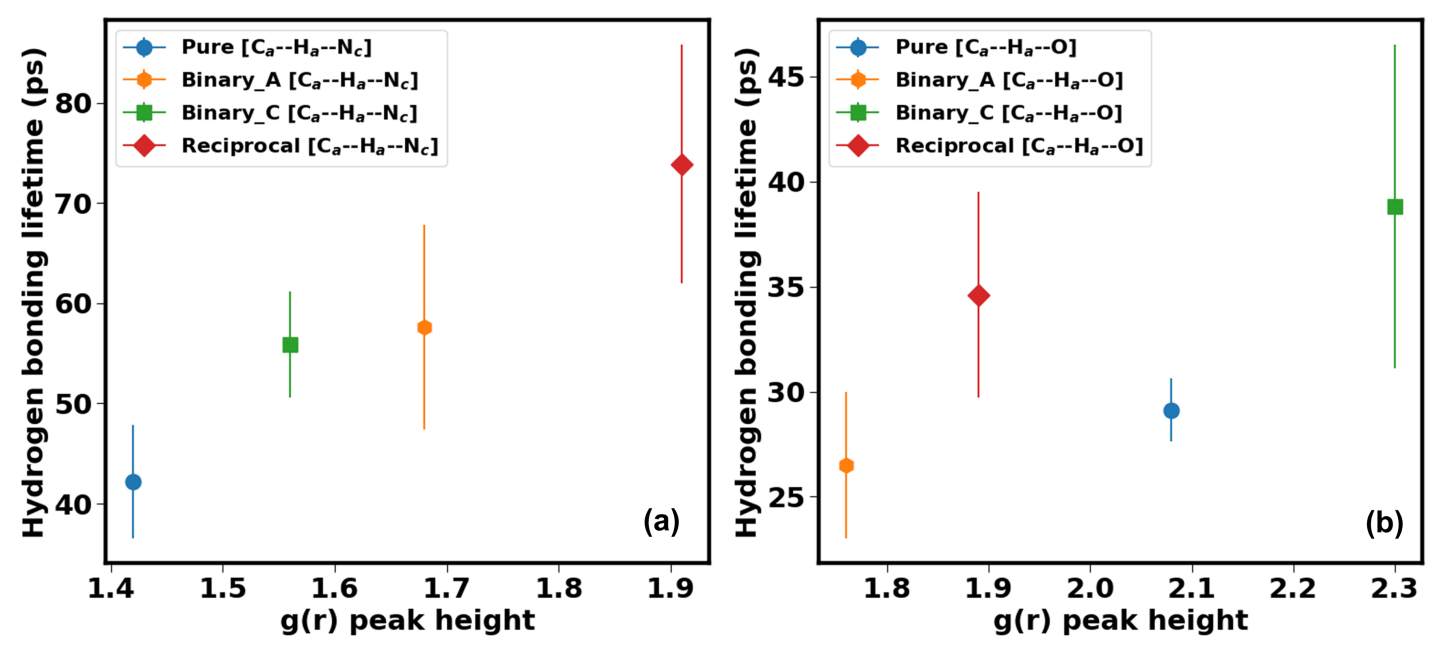

Figure 6: Correlation between hydrogen bonding lifetime and RDF peak height of the first solvation shell of hydrogen bonding sites. (a) $\left[\mathrm{C}_{2} \mathrm{mim}\right]--[\mathrm{DCA}]$. (b) $\left[\mathrm{C}_{2} \mathrm{mim}\right]--\left[\mathrm{NTf}_{2}\right]$. Binary_A refers to $\left[\mathrm{C}_{2} \mathrm{mim}\right][\mathrm{DCA}]\left[\mathrm{NTf}_{2}\right]$ system, Binary_C refers to $\left[\mathrm{C}_{2} \mathrm{mim}\right]\left[\mathrm{C}_{6} \mathrm{mim}\right][\mathrm{DCA}]$ or $\left[\mathrm{C}_{2} \mathrm{mim}\right]\left[\mathrm{C}_{6} \mathrm{mim}\right]\left[\mathrm{NTf}_{2}\right]$ system and Reciprocal refers to $\left[\mathrm{C}_{2} \mathrm{mim}\right]\left[\mathrm{C}_{6} \mathrm{mim}\right][\mathrm{DCA}]\left[\mathrm{NTf}_{2}\right]$ system.

\section{Self Diffusion Constant}

The self-diffusion constant of the ions was obtained by fitting the linear region of the mean square displacement (MSD) using the following equation.

$$
D=\frac{1}{6} \lim _{t \rightarrow \infty} \frac{d}{d t}\left\langle\sum_{i=1}^{N}\left[\vec{r}_{i}(t)-\vec{r}_{i}(0)\right]^{2}\right\rangle
$$

where, $\vec{r}_{i}(t)$ is the position of an ion at any given time, $\langle\ldots\rangle$ is the average of the ensemble, and $D$ is the self-diffusion constant. To determine the linear region for the fit, the MSD values were divided into three blocks spanning 0-10 ns, 10-15 ns and 15-20 ns for the final 
$N P T$ production run. Over these blocks, we computed the non-Gaussian parameter $\beta(t)$ :

$$
\beta(t)=\frac{\mathrm{d} \ln \left\langle\Delta r^{2}(t)\right\rangle}{\mathrm{d} \ln (t)} .
$$

A linear regime is indicated as $\beta(t)$ approaches a value of unity, which, for most systems occurred over the 10-15 ns block, as assessed from the slope of the log-log plot MSD versus time (please refer to Figures S13 - S16) The reported values of self-diffusion coefficients were calculated by tracking the MSD over this timeframe.

Table 3 summarizes the average self-diffusion constant of ions for pure, binary, and recipTable 3: Self Diffusion constant $\left(D \times 10^{-7} \mathrm{~cm}^{2} / \mathrm{sec}\right)$ of ions for pure, binary and reciprocal mixtures at $323 \mathrm{~K}$.

\begin{tabular}{|c|c|c|c|c|}
\hline System & & Self Diffus & on constant & \\
\hline & {$\left[\mathrm{C}_{2} \mathrm{mim}\right]^{+}$} & {$\left[\mathrm{C}_{6} \mathrm{mim}\right]^{+}$} & {$[\mathrm{DCA}]^{-}$} & {$\left[\mathrm{NTf}_{2}\right]^{-}$} \\
\hline$\left[\mathrm{C}_{2} \operatorname{mim}\right][\mathrm{DCA}]$ & $10.64 \pm 0.67[12.8]^{\mathrm{a}}$ & & $12.29 \pm 0.14[14.6]^{\mathrm{a}}$ & \\
\hline$\left[\mathrm{C}_{2} \operatorname{mim}\right]\left[\mathrm{NTf}_{2}\right]$ & $7.85 \pm 1.61[10.6]^{\mathrm{c}}$ & & & $6.22 \pm 1.56[6.91]^{\mathrm{c}}$ \\
\hline$\left[\mathrm{C}_{6} \mathrm{mim}\right][\mathrm{DCA}]$ & & $3.75 \pm 0.32[8.4]^{\mathrm{b}}$ & $4.92 \pm 0.30[9.6]^{\mathrm{b}}$ & \\
\hline$\left[\mathrm{C}_{6} \operatorname{mim}\right]\left[\mathrm{NTf}_{2}\right]$ & & $4.48 \pm 1.20[4.64]^{\mathrm{c}}$ & & $3.90 \pm 0.93[4.31]^{\mathrm{c}}$ \\
\hline$\left[\mathrm{C}_{2} \operatorname{mim}\right]\left[\mathrm{C}_{6} \operatorname{mim}\right][\mathrm{DCA}]$ & $7.84 \pm 0.54$ & $5.38 \pm 0.02$ & $7.72 \pm 0.41$ & \\
\hline$\left[\mathrm{C}_{2} \operatorname{mim}\right]\left[\mathrm{C}_{6} \operatorname{mim}\right]\left[\mathrm{NTf}_{2}\right]$ & $6.77 \pm 1.55$ & $5.3 \pm 1.48$ & & $4.59 \pm 1.08$ \\
\hline$\left[\mathrm{C}_{2} \operatorname{mim}\right][\mathrm{DCA}]\left[\mathrm{NTf}_{2}\right]$ & $8.63 \pm 0.57$ & & $10.24 \pm 1.02$ & $6.89 \pm 0.77$ \\
\hline$\left[\mathrm{C}_{6} \operatorname{mim}\right][\mathrm{DCA}]\left[\mathrm{NTf}_{2}\right]$ & & $3.28 \pm 0.19$ & $4.07 \pm 0.46$ & $2.67 \pm 0.12$ \\
\hline$\left[\mathrm{C}_{2} \mathrm{mim}\right]\left[\mathrm{C}_{6} \mathrm{mim}\right][\mathrm{DCA}]\left[\mathrm{NTf}_{2}\right]$ & $\left.\mathrm{f}_{2}\right] \quad 6.14 \pm 0.60$ & $4.83 \pm 0.29$ & $6.37 \pm 0.55$ & $4.10 \pm 0.15$ \\
\hline
\end{tabular}

rocal mixtures at $323.0 \mathrm{~K}$ obtained from this study along with a comparison of self-diffusion constant data obtained from MD simulation in literature and NMR diffusion experiements. The self-diffusion constant for the cation and anion in pure $\left[\mathrm{C}_{2} \mathrm{mim}\right][\mathrm{DCA}]$ show an interesting trend where the self-diffusion coefficient of the anion is greater than that of the cation, a trend that is opposite for many imidazolium-based ionic liquids. ${ }^{47}$ This is primarily because of the smaller size and planar shape of the $[\mathrm{DCA}]^{-}$anion that allows it to easily diffuse 
through the ionic network. Goloviznina et al. reported a similar trend for $\left[\mathrm{C}_{2} \mathrm{mim}\right][\mathrm{DCA}] .{ }^{29}$ The authors emploiyed \pm 0.8 charge scaling as in this work, which results in a considerable speeding up of the dynamics and an improvement in the self-diffusion coefficients compared to \pm 1.0 scaling for the electrostatic interactions. The self-diffusion coefficients for both the cation and anion in $\left[\mathrm{C}_{6} \mathrm{mim}\right][\mathrm{DCA}]$ drop by a factor of 2.4 compared to the self-diffusion coefficients of ions in $\left[\mathrm{C}_{2} \mathrm{mim}\right][\mathrm{DCA}]$. The reduction in the self-diffusion coefficient is similar to the ratio of the viscosity of $\left[\mathrm{C}_{2} \mathrm{mim}\right][\mathrm{DCA}]$ to that of $\left[\mathrm{C}_{6} \mathrm{mim}\right][\mathrm{DCA}]$ and is in line with change in the hydrogen bonding lifetimes for these ionic liquids. Switching the anion from [DCA $]^{-}$ to $\left[\mathrm{NTf}_{2}\right]^{-}$leads to a decrease in ionic self-diffusion coefficients despite the hydrogen bonding lifetime being smaller than that for $\left[\mathrm{C}_{2} \mathrm{mim}\right][\mathrm{DCA}]$, which suggests that additional factors such as the bulkier size of the anion and a propensity for anion- $\pi$ interactions also contribute to determining dynamics in $\left[\mathrm{C}_{2} \mathrm{mim}\right]\left[\mathrm{NTf}_{2}\right]$. Consistent with findings in the literature, results from our simulations indicate that the cation diffuses faster than the anion in the pure ionic liquid systems containing $\left[\mathrm{NTf}_{2}\right]^{-}$as the anion. Similar to the $[\mathrm{DCA}]^{-}$systems, substituting $\left[\mathrm{C}_{2} \mathrm{mim}\right]^{+}$cation with $\left[\mathrm{C}_{6} \mathrm{mim}\right]^{+}$causes slowing down of the dynamics for both the ions. The calculated self-diffusion coefficients for the ions in $\left[\mathrm{C}_{2} \mathrm{mim}\right]\left[\mathrm{NTf}_{2}\right]$ and $\left[\mathrm{C}_{6} \mathrm{mim}\right]\left[\mathrm{NTf}_{2}\right]$ agree reasonably well with those computed from the parameters of the VFT equation derived by Tokuda et al. ${ }^{47}$ For binary and reciprocal mixtures, we see that the species exhibiting higher self-diffusion coefficient slows down, while the self-diffusion coefficients of the slower moving ions either remains nearly identical or increases with respect to their respective values for the pure ionic liquids, e.g., the self-diffusion coefficients of $\left[\mathrm{C}_{2} \mathrm{mim}\right]^{+}$and $[\mathrm{DCA}]^{-}$are lower, while that of $\left[\mathrm{C}_{6} \mathrm{mim}\right]^{+}$enhances in $\left[\mathrm{C}_{2} \mathrm{mim}\right]\left[\mathrm{C}_{6} \mathrm{mim}\right][\mathrm{DCA}]$ mixture relative to those in pure systems. A similar observation can be made for the $\left[\mathrm{C}_{2} \mathrm{mim}\right][\mathrm{DCA}]\left[\mathrm{NTf}_{2}\right]$ system. We also calculated the overall diffusion coefficients for the pure, binary, and reciprocal mixtures using the Eqs. $12-15$ to quantify the dynamics:

$$
D=\frac{D_{+}+D_{-}}{2}
$$




$$
\begin{gathered}
D=\frac{D_{+}+x *\left(D_{1-}+D_{2-}\right)}{2} \\
D=\frac{x *\left(D_{1+}+D_{2+}\right)+D_{-}}{2} \\
D=\frac{x *\left(D_{1+}+D_{2+}+D_{1-}+D_{2-}\right)}{2}
\end{gathered}
$$

The results for the overall diffusion constant of the system are displayed in Figure 7. As expected from the individual ions self-diffusion coefficients, $\left[\mathrm{C}_{2} \mathrm{mim}\right][\mathrm{DCA}]$ has the fastest dynamics compared to all the systems. This is again because of the pairing between short alkyl chain cation and a smaller size anion that does not hinder the movement of ions leading to faster diffusion. Changing the $[\mathrm{DCA}]^{-}$anion to bulkier $\left[\mathrm{NTf}_{2}\right]^{-}$however reduces the overall diffusion of the system significantly. The effect of replacing the $\left[\mathrm{C}_{2} \mathrm{mim}\right]^{+}$cation with $\left[\mathrm{C}_{6} \mathrm{mim}\right]^{+}$has a more pronounced effect on the overall dynamics of the ionic liquid. For the binary ionic liquid mixtures, the collective dynamics falls in between the dynamics of the constituent ionic liquids. 


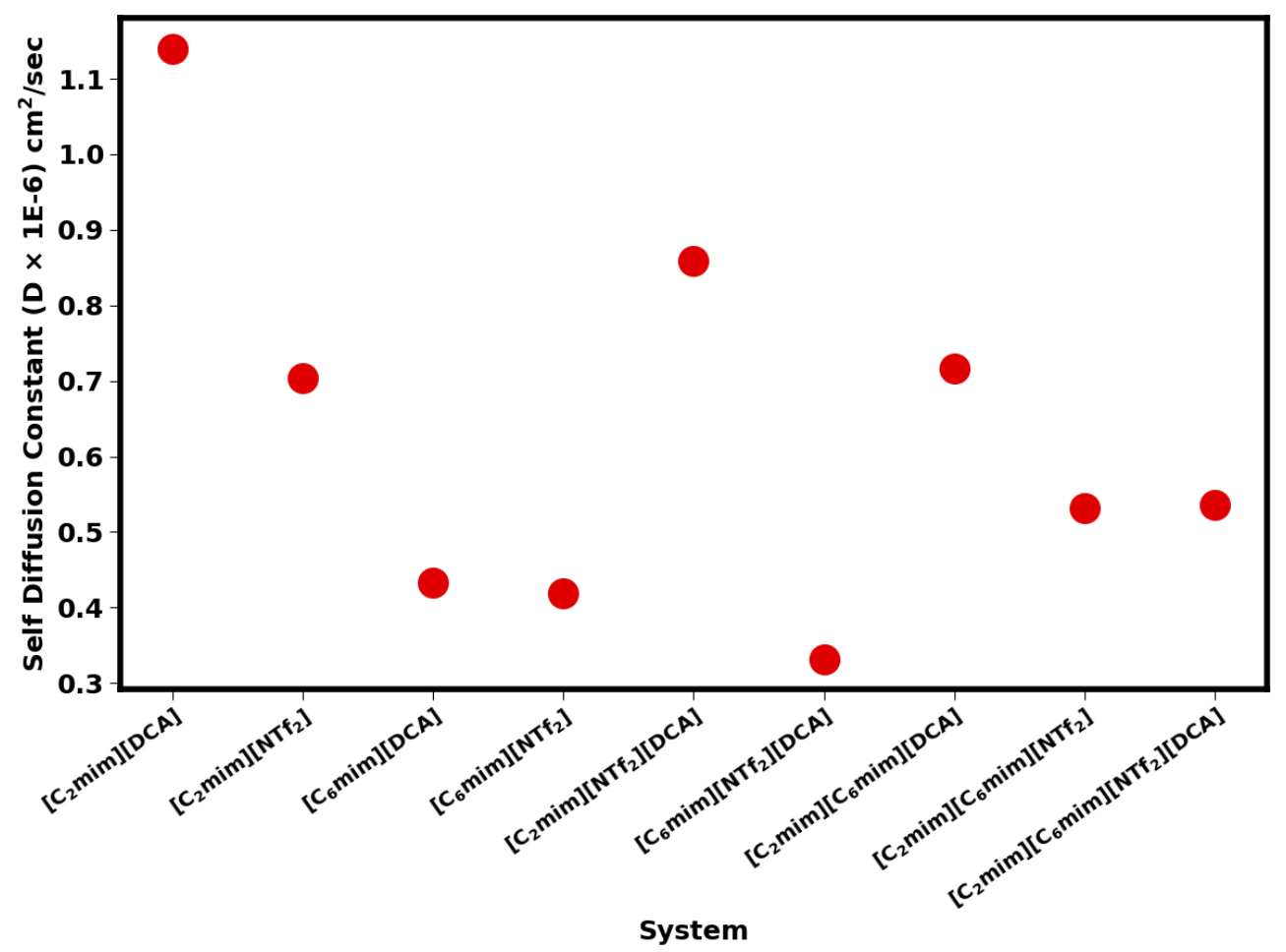

Figure 7: Self Diffusion constant of all the systems calculated using equation equation 12, 14,13 and 15 .

\section{Conclusion}

In this work, we performed MD simulations on various systems of pure ionic liquids [ $\left.\mathrm{C}_{2} \mathrm{mim}\right][\mathrm{DCA}]$, $\left[\mathrm{C}_{6} \operatorname{mim}\right][\mathrm{DCA}],\left[\mathrm{C}_{2} \mathrm{mim}\right]\left[\mathrm{NTf}_{2}\right],\left[\mathrm{C}_{6} \mathrm{mim}\right]\left[\mathrm{NTf}_{2}\right]$, and equimolar binary and reciprocal mixtures resulting from them. We characterized these systems in terms of the ionic centerof-mass radial distribution functions (RDF), hydrogen bonding bonding interactions and corresponding hydrogen bonding lifetimes, and self-diffusion coefficients. We observed that the $\mathrm{RDF}$ between $[\mathrm{DCA}]^{-}$with $\left[\mathrm{C}_{2} \mathrm{mim}\right]^{+}$displayed the highest first peak intensity in the reciprocal mixture followed by that in the binary anion mixture, binary cation mixture, and pure ionic liquid system, indicating that the association of the $[\mathrm{DCA}]^{-}$with $\left[\mathrm{C}_{2} \mathrm{mim}\right]^{+}$could be tuned through the addition of a cation, anion, or both to $\left[\mathrm{C}_{2} \mathrm{mim}\right][\mathrm{DCA}]$. Further, evaluation of the hydrogen bonding site-site RDF interaction exhibited a similar enhancement in the first peak intensity, revealing the role of hydrogen bonding in preferential interac- 
tion. The first peak intensity in the center-of-mass RDF of $\left[\mathrm{C}_{2} \mathrm{mim}\right]-\left[\mathrm{NTf}_{2}\right]$ in the reciprocal mixture, however, was found to be less than that for the pure ionic liquid $\left[\mathrm{C}_{2} \mathrm{mim}\right]\left[\mathrm{NTf}_{2}\right]$, providing additional evidence of the preferential interaction of $\left[\mathrm{C}_{2} \mathrm{mim}\right]^{+}$with the anion possessing higher hydrogen bonding ability.

We also demonstrated that the preference for $[\mathrm{DCA}]^{-}$to associate with $\left[\mathrm{C}_{2} \mathrm{mim}\right]^{+}$translates into an increase in the hydrogen bonding lifetimes in binary and reciprocal mixtures. In fact, the hydrogen bonding lifetime in the reciprocal mixture is almost twice that for the pure ionic liquid system. Although the hydrogen bonding lifetime for $\left[\mathrm{C}_{2} \mathrm{mim}\right]-\left[\mathrm{NTf}_{2}\right]$ also increases when mixtures are considered, the enhancement is non-monotonic. The hydrogen bonding lifetime for the $\left[\mathrm{C}_{2} \mathrm{mim}\right]-\left[\mathrm{NTf}_{2}\right]$ interaction stayed relatively the same or reduced in the presence of $[\mathrm{DCA}]^{-}$anion, suggesting that this preferential interaction only occurs for the short alkyl chain cation and the strongly coordinating anion. The overall dynamics of the various systems, as analyzed from the diffusion coefficients, revealed trends similar to the hydrogen bonding lifetimes, with the exception of pure $\left[\mathrm{C}_{2} \operatorname{mim}\right][\mathrm{DCA}]$ and $\left[\mathrm{C}_{2} \mathrm{mim}\right]\left[\mathrm{NTf}_{2}\right]$ systems, which was explained in terms of the ability of $\left[\mathrm{NTf}_{2}\right]^{-}$to participate in additional modes of interaction with the cation.

Our study provides molecular-level details on the emergence of preferential ionic interactions and their implications on the hydrogen bonding between ion pairs in the binary and reciprocal mixtures, opening up possibilities for inducing non-idealities in such systems. From a practical point of view, as hydrogen bonding interactions are intimately connected to physicochemical properties of ionic liquids, the present work exemplifies a pathway for designing task-specific ionic liquid mixtures by combining cations with differing in the length of the alkyl chain length and/or anions possessing widely different hydrogen bonding abilities. 


\section{Acknowledgement}

Authors acknowledge funding for this work from the National Science Foundation grant

CBET-1706978. The computing for this project was performed at the High Performance

Computing Center at Oklahoma State University supported in part through the National

Science Foundation grant OAC-1531128.

\section{Supporting Information Available}

\section{References}

(1) Stoppa, A.; Buchner, R.; Hefter, G. How ideal are binary mixtures of room-temperature ionic liquids? Journal of Molecular Liquids 2010, 153, 46-51.

(2) Bruessel, M.; Brehm, M.; Pensado, A. S.; Malberg, F.; Ramzan, M.; Stark, A.; Kirchner, B. On the ideality of binary mixtures of ionic liquids. Physical Chemistry Chemical Physics 2012, 14, 13204-13215.

(3) Niedermeyer, H.; Hallett, J. P.; Villar-Garcia, I. J.; Hunt, P. A.; Welton, T. Mixtures of ionic liquids. Chemical Society Reviews 2012, 41, 7780-7802.

(4) Dhakal, P.; Shah, J. K. Recent advances in molecular simulations of ionic liquid-ionic liquid mixtures. Current Opinion in Green and Sustainable Chemistry 2019, 18, 90-97.

(5) Kapoor, U.; Shah, J. K. Macroscopic Differentiators for Microscopic Structural Nonideality in Binary Ionic Liquid Mixtures. The Journal of Physical Chemistry B 2020, 124, 7849-7856.

(6) Brooks, N. J.; Castiglione, F.; Doherty, C. M.; Dolan, A.; Hill, A. J.; Hunt, P. A.; Matthews, R. P.; Mauri, M.; Mele, A.; Simonutti, R., et al. Linking the structures, free volumes, and properties of ionic liquid mixtures. Chemical science 2017, 8, 6359-6374. 
(7) Kapoor, U.; Shah, J. K. Preferential ionic interactions and microscopic structural changes drive nonideality in binary ionic liquid mixtures as revealed from molecular simulations. Industrial \& Engineering Chemistry Research 2016, 55, 13132-13146.

(8) Xiao, D.; Rajian, J. R.; Hines Jr, L. G.; Li, S.; Bartsch, R. A.; Quitevis, E. L. Nanostructural organization and anion effects in the optical Kerr effect spectra of binary ionic liquid mixtures. The Journal of Physical Chemistry B 2008, 112, 13316-13325.

(9) Voroshylova, I. V.; Ferreira, E. S.; Malček, M.; Costa, R.; Pereira, C. M.; Cordeiro, M. N. D. Influence of the anion on the properties of ionic liquid mixtures: a molecular dynamics study. Physical Chemistry Chemical Physics 2018, 20, 14899-14918.

(10) Wang, X.; Huang, Y.; Li, L.; Huang, L.; Chen, X.; Yang, Z. Molecular-level insights into composition-dependent structure, dynamics, and hydrogen bonds of binary ionic liquid mixture from molecular dynamics simulations. Chemical Physics 2021, 542, 111051.

(11) Gehrke, S.; von Domaros, M.; Clark, R.; Hollóczki, O.; Brehm, M.; Welton, T.; Luzar, A.; Kirchner, B. Structure and lifetimes in ionic liquids and their mixtures. Faraday Discussions 2018, 206, 219-245.

(12) Navia, P.; Troncoso, J.; Romaní, L. Excess magnitudes for ionic liquid binary mixtures with a common ion. Journal of Chemical \&3 Engineering Data 2007, 52, 1369-1374.

(13) Navia, P.; Troncoso, J.; Romaní, L. Viscosities for ionic liquid binary mixtures with a common ion. Journal of solution chemistry 2008, 37, 677-688.

(14) Fox, E. T.; Weaver, J. E.; Henderson, W. A. Tuning binary ionic liquid mixtures: linking alkyl chain length to phase behavior and ionic conductivity. The Journal of Physical Chemistry C 2012, 116, 5270-5274.

(15) Shimizu, K.; Tariq, M.; Rebelo, L. P.; Lopes, J. N. C. Binary mixtures of ionic liq- 
uids with a common ion revisited: a molecular dynamics simulation study. Journal of Molecular Liquids 2010, 153, 52-56.

(16) Weber, C. C.; Brooks, N. J.; Castiglione, F.; Mauri, M.; Simonutti, R.; Mele, A.; Welton, T. On the structural origin of free volume in 1-alkyl-3-methylimidazolium ionic liquid mixtures: A SAXS and 129 Xe NMR study. Physical Chemistry Chemical Physics 2019, 21, 5999-6010.

(17) Kapoor, U.; Shah, J. K. Globular, sponge-like to layer-like morphological transition in 1-n-alkyl-3-methylimidazolium octylsulfate ionic liquid homologous series. The Journal of Physical Chemistry B 2018, 122, 213-228.

(18) Bruce, D. W.; Cabry, C. P.; Canongia Lopes, J. N.; Costen, M. L.; D'Andrea, L.; Grillo, I.; Marshall, B. C.; McKendrick, K. G.; Minton, T. K.; Purcell, S. M., et al. Nanosegregation and Structuring in the Bulk and at the Surface of Ionic-Liquid Mixtures. The Journal of Physical Chemistry B 2017, 121, 6002-6020.

(19) Cosby, T.; Kapoor, U.; Shah, J. K.; Sangoro, J. Mesoscale organization and dynamics in binary ionic liquid mixtures. The journal of physical chemistry letters 2019, 10, $6274-6280$.

(20) Wang, X.; Fu, F.; Peng, K.; Yang, Z.; Hu, N.; Chen, X.; Li, W. Understanding of structures, dynamics, and hydrogen bonds of imidazolium-based ionic liquid mixture from molecular dynamics simulation. Chemical Physics 2019, 525, 110391.

(21) Mirarabrazi, M.; Stolarska, O.; Smiglak, M.; Robelin, C. Solid-liquid equilibria for a pyrrolidinium-based common-cation ternary ionic liquid system, and for a pyridiniumbased ternary reciprocal ionic liquid system: an experimental study and a thermodynamic model. Physical Chemistry Chemical Physics 2018, 20, 637-657.

(22) Clough, M. T.; Crick, C. R.; Gräsvik, J.; Hunt, P. A.; Niedermeyer, H.; Welton, T.; 
Whitaker, O. P. A physicochemical investigation of ionic liquid mixtures. Chemical science 2015, 6, 1101-1114.

(23) Taige, M.; Hilbert, D.; Schubert, T. J. Mixtures of ionic liquids as possible electrolytes for lithium ion batteries. Zeitschrift für physikalische Chemie 2012, 226, 129-139.

(24) Bharmoria, P.; Damarla, K.; Trivedi, T. J.; Malek, N. I.; Kumar, A. A reciprocal binary mixture of protic/aprotic ionic liquids as a deep eutectic solvent: physicochemical behaviour and application towards agarose processing. $R S C$ advances $\mathbf{2 0 1 5}, 5,99245-$ 99252.

(25) Sappidi, P.; Bara, J. E.; Turner, C. H. Molecular-level behavior of imidazolium-based ionic liquid mixtures. Chemical Engineering Science 2021, 229, 116073.

(26) Canongia Lopes, J. N.; Deschamps, J.; Pádua, A. A. Modeling ionic liquids using a systematic all-atom force field. The journal of physical chemistry B 2004, 108, 20382047.

(27) Canongia Lopes, J. N.; Pádua, A. A. Molecular force field for ionic liquids III: Imidazolium, pyridinium, and phosphonium cations; chloride, bromide, and dicyanamide anions. The Journal of Physical Chemistry B 2006, 110, 19586-19592.

(28) Canongia Lopes, J. N.; Pádua, A. A. Molecular force field for ionic liquids composed of triflate or bistriflylimide anions. The Journal of Physical Chemistry B 2004, 108, $16893-16898$.

(29) Goloviznina, K.; Canongia Lopes, J. N.; Costa Gomes, M.; Pádua, A. A. Transferable, polarizable force field for ionic liquids. Journal of chemical theory and computation 2019, 15, 5858-5871.

(30) Gehrke, S.; von Domaros, M.; Clark, R.; Hollóczki, O.; Brehm, M.; Welton, T.; 
Luzar, A.; Kirchner, B. Structure and lifetimes in ionic liquids and their mixtures. Faraday discussions 2017, 206, 219-245.

(31) Bekker, H.; Berendsen, H.; Dijkstra, E.; Achterop, S.; Van Drunen, R.; Van der Spoel, D.; Sijbers, A.; Keegstra, H.; Reitsma, B.; Renardus, M. Gromacs: A parallel computer for molecular dynamics simulations. 1993, 92, 252-256.

(32) Hess, B.; Kutzner, C.; Van Der Spoel, D.; Lindahl, E. GROMACS 4: algorithms for highly efficient, load-balanced, and scalable molecular simulation. Journal of Chemical Theory and computation 2008, 4, 435-447.

(33) Martínez, L.; Andrade, R.; Birgin, E. G.; Martínez, J. M. PACKMOL: a package for building initial configurations for molecular dynamics simulations. Journal of computational chemistry 2009, 30, 2157-2164.

(34) Nosé, S. A molecular dynamics method for simulations in the canonical ensemble. Molecular physics 1984, 52, 255-268.

(35) Parrinello, M.; Rahman, A. Polymorphic transitions in single crystals: A new molecular dynamics method. Journal of Applied physics 1981, 52, 7182-7190.

(36) Doherty, B.; Zhong, X.; Gathiaka, S.; Li, B.; Acevedo, O. Revisiting OPLS force field parameters for ionic liquid simulations. Journal of chemical theory and computation 2017, 13, 6131-6145.

(37) Nasrabadi, A. T.; Gelb, L. D. Structural and transport properties of tertiary ammonium triflate ionic liquids: A molecular dynamics study. The Journal of Physical Chemistry B 2017, 121, 1908-1921.

(38) Matthews, R. P.; Villar-Garcia, I. J.; Weber, C. C.; Griffith, J.; Cameron, F.; Hallett, J. P.; Hunt, P. A.; Welton, T. A structural investigation of ionic liquid mixtures. Physical Chemistry Chemical Physics 2016, 18, 8608 - 8624. 
(39) Brehm, M.; Thomas, M.; Gehrke, S.; Kirchner, B. TRAVIS-A free analyzer for trajectories from molecular simulation. The Journal of chemical physics 2020, 152, 164105.

(40) Gehrke, S.; Kirchner, B. Robustness of the hydrogen bond and ion pair dynamics in ionic liquids to different parameters from the reactive flux method. Journal of Chemical E Engineering Data 2019, 65, 1146-1158.

(41) Reddy, T. D. N.; Mallik, B. S. Protic ammonium carboxylate ionic liquids: insight into structure, dynamics and thermophysical properties by alkyl group functionalization. Physical Chemistry Chemical Physics 2017, 19, 10358-10370.

(42) Freire, M. G.; Teles, A. R. R.; Rocha, M. A.; Schroíder, B.; Neves, C. M.; Carvalho, P. J.; Evtuguin, D. V.; Santos, L. M.; Coutinho, J. A. Thermophysical characterization of ionic liquids able to dissolve biomass. Journal of Chemical $\&$ Engineering Data 2011, $56,4813-4822$.

(43) Seoane, R. G.; Corderí, S.; Goémez, E.; Calvar, N.; Gonzaélez, E. J.; Macedo, E. A.; Domínguez, Á. Temperature dependence and structural influence on the thermophysical properties of eleven commercial ionic liquids. Industrial \& engineering chemistry research 2012, 51, 2492-2504.

(44) Ahosseini, A.; Scurto, A. M. Viscosity of imidazolium-based ionic liquids at elevated pressures: cation and anion effects. International Journal of Thermophysics 2008, 29, $1222-1243$.

(45) Widegren, J. A.; Magee, J. W. Density, viscosity, speed of sound, and electrolytic conductivity for the ionic liquid 1-hexyl-3-methylimidazolium bis (trifluoromethylsulfonyl) imide and its mixtures with water. Journal of Chemical \& Engineering Data 2007, 52, $2331-2338$.

(46) Zhang, Y.; Maginn, E. J. Direct Correlation between Ionic Liquid Transport Properties 
and Ion Pair Lifetimes: A Molecular Dynamics Study. J. Phys. Chem. Lett. 2015, 6, $700-705$.

(47) Tokuda, H.; Hayamizu, K.; Ishii, K.; Susan, M. A. B. H.; Watanabe, M. Physicochemical properties and structures of room temperature ionic liquids. 2. Variation of alkyl chain length in imidazolium cation. The Journal of Physical Chemistry B 2005, 109, 61036110. 


\section{Graphical TOC Entry}

Some journals require a graphical entry for the Table of Contents. This should be laid out "print ready" so that the sizing of the text is correct.

Inside the tocentry environment, the font used is Helvetica 8 pt, as required by Journal of the American Chemical Society.

The surrounding frame is $9 \mathrm{~cm}$ by $3.5 \mathrm{~cm}$, which is the maximum permitted for Journal of the American Chemical Society graphical table of content entries. The box will not resize if the content is too big: instead it will overflow the edge of the box.

This box and the associated title will always be printed on a separate page at the end of the document. 